\title{
Evaluation of Local and Systemic Levels of Vitamin D3 and Fibroblast Growth Factor \\ 23 After Non-Surgical Periodontal Therapy
}

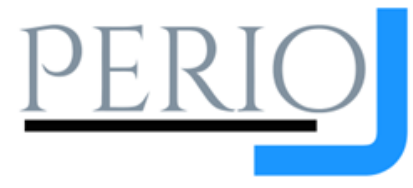

\section{Dalia M. Ghalwash, ${ }^{A}$ Olfat G. Shaker, ${ }^{B}$ Enji A. Mahmoud ${ }^{C}$}

A Associate Professor, Department of Oral Medicine and

Periodontology, Faculty of Dentistry, The British University in

Egypt, Cairo, Egypt.

B Professor, Department of Biochemistry, Faculty of Medicine, Cairo University, Cairo, Egypt.

${ }^{\mathrm{C}}$ Associate Professor, Department of Oral Medicine and Periodontology, Faculty of Dentistry, Cairo University, Cairo, Egypt.

\section{Accepted for publication:}

July 15, 2019

\begin{abstract}
Background: Vitamin $D$ is an important micronutrient possessing valuable and diverse biological effects that are related to periodontal disease pathogenesis. Vitamin D levels are regulated by fibroblast growth factor 23 (FGF23) which is strongly associated with inflammation. The aim of the present study was to explore the relation of vitamin D and FGF23 with periodontal disease through the assessment of their levels in gingival crevicular fluid (GCF) and serum in periodontitis patients before and after non-surgical periodontal therapy and to compare those levels with healthy controls in order to identify any possible correlation between them. Methods: Serum and GCF samples were collected at baseline and 3 months after therapy to evaluate levels of vitamin D3 and FGF23 using enzyme-linked immunosorbent assay (ELISA) in both study groups. Group I consisted of 15 controls who were systematically and periodontally healthy, while group II consisted of 15 subjects who were systematically healthy with stage II periodontitis. Results: A significant elevation in vitamin D3 levels in both GCF and serum were recorded 3 months after therapy with a $25.98 \%$ and $39.29 \%$ increase respectively. On the contrary, a significant reduction in mean values of FGF23 in both GCF and serum were found after treatment with a $49.75 \%$ and $39.28 \%$ decrease respectively. Conclusion: The results of the present investigation have shed light on a vital association of both FGF23 and vitamin D3 with periodontitis, where FGF23 is associated with periodontal inflammation and vitamin D3 is associated with periodontal health.
\end{abstract}

Keywords: Vitamin D; FGF23; inflammation; periodontitis.

\section{Introduction}

The onset and progression of periodontal disease are influenced by the delicate equilibrium between microbial virulence factors and the proportional reaction of the host. In this regard, nutritional factors may be very noteworthy since they have been implicated in several chronic inflammatory conditions that are interrelated with periodontitis, including type 2 diabetes, inflammatory bowel disease, rheumatoid arthritis, and cardiovascular diseases. Micronutrients including vitamins, amino acids, trace elements, and minerals are required only in small quantities by living organisms and are indispensable for human development and well-being. ${ }^{1}$ Among these important micronutrients, vitamin $D$ occupies a distinguished place with its valuable and diverse biological effects.

Vitamin $D$ is a secosteroid prohormone that can be manufactured by skin cells exposed to ultraviolet (UV) radiation or ingested through normal dietary consumption. Vitamin $D$ occurs in two forms namely D2 (ergocalciferol) and D3 (cholecalciferol). ${ }^{2}$ Vitamin D3 is further hydroxylated in the liver into 25-hydroxyvitamin D3 $(25(\mathrm{OH}) \mathrm{D} 3)$, which is the most steady form of vitamin $D$ in blood. ${ }^{3}$ Besides the well-known role of sustaining the equilibrium of calcium and phosphorus levels in blood, it also has an endorsing effect on bone remodeling. 3,4 Low vitamin $D$ levels are associated with a negative calcium balance, disturbed bone mineralization, and bone loss. ${ }^{5}$ Vitamin D3 is also vital to the 
immune system as it augments the innate immune response by activating hydrogen peroxide secretion in monocytes, and stimulating neutrophils, monocytes, macrophages, and dendritic cells to synthesize antimicrobial peptides, as defensin and cathelicidin LL-37, which has an important role in promoting chemotaxis, the release of chemokines and cytokines, neutralization of bacterial endotoxins, wound healing, and increasing vascular permeability. ${ }^{1,6}$

Vitamin D3 influences the specific immune response as well by affecting both humoral and cellular immunity which specifically extinguish various pathogens that are presented to them via macrophages and dendritic cells. As much as such immune processes protect the host against infections, they also harm periodontal tissue and might worsen the periodontal condition. Vitamin $D$ suppresses $T$ lymphocyte proliferation and $B$ lymphocyte transformation into plasma cells and inhibits their antibody production, thus suppressing the overall unwanted effects. Moreover, vitamin D prevents the excessive specific immune response through the inhibition of cytokine release during bacterial invasion as interleukin (IL)-1, IL-6, IL-8, IL-12, and tumor necrosis factor (TNF) which are responsible for lymphocyte infiltration, deterioration of extracellular matrix, and bone resorption. 5,7 Therefore, vitamin $D$ affects periodontal disease pathogenesis through immunomodulation, enhancing bone mineralization, decreasing bone resorption, and augmenting the fight against periodontal pathogens. ${ }^{8}$ The anti-inflammatory properties of vitamin $D$ were also confirmed in previous studies where serum with higher vitamin D concentrations was found to contain less IL-6 and leptin and more adiponectin, which inhibits nuclear factor-kappa B (NF-KB) and IL-6 production, and induces anti-inflammatory cytokines IL-10 and IL-1 receptor antagonist (IL$1 \mathrm{Ra}) .{ }^{9}$

The fibroblast growth factors (FGF) family comprises 22 growth factors, with diverse functions in development and health, including the regulation of cell proliferation, differentiation, organogenesis, metabolism, and repair. ${ }^{10}$ Fibroblast growth factors are divided into seven subgroups and are classified as paracrine, endocrine, and intracrine based on their action mechanisms. ${ }^{11}$ Fibroblast growth factor 23 is a recently discovered FGF which is produced under physiological circumstances by osteoblasts and osteocytes and functions as a circulating bonederived hormone that maintains phosphate homeostasis by binding to its receptor and klotho - its coreceptor in the parathyroid glands and kidney; therefore, it is designated as an endocrine FGF. ${ }^{10,12}$ The biologically active form of FGF23 is a $32 \mathrm{kDa}$ glycoprotein with a halflife of about 45-60 minutes in humans. ${ }^{13}$

Osteocytes produce FGF23 in response to dietary intake of phosphate, and FGF23 will in turn increase phosphate excretion by the kidney. ${ }^{14,15}$ Additionally, FGF23 decreases circulating vitamin $D$ levels by inhibiting 1- $\alpha$ hydroxylase in the kidney, which converts the prehormone 25-hydroxyvitamin D3 into the active hormone, 1,25-dihydroxyvitamin D3 $(1,25(\mathrm{OH}) 2 \mathrm{D} 3)$, and by augmenting 24hydroxylase production, which degrades 1,25dihydroxyvitamin D3 into the inactive form. ${ }^{13,15}$ Fibroblast growth factor 23 also inhibits parathyroid hormone (PTH) secretion. ${ }^{16}$ Consequently, FGF23 is considered a key regulator of vitamin $D$ metabolism.

Fibroblast growth factor 23 might also possess relevant physiological effects on bone mineralization by suppressing mRNA transcription of tissue-nonspecific alkaline phosphatase (TNAP) which regulates bone mineralization through cleaving the mineralization inhibitor pyrophosphate that osteoblasts secrete to avoid premature mineralization of osteoid.17,18 Therefore, it can be presumed that production of FGF23 in osteocytes locally may not only contribute to compromised mineralization when excessively secreted in bone, but may also inhibit bone mineralization by down regulating TNAP expression. ${ }^{17,19}$

Fibroblast growth factor 23 impairs the host defense against infections via inhibition of neutrophil recruitment which is the predominant leukocyte subset of the innate immune response. ${ }^{10}$ Fibroblast growth factor 23 also stops $\beta 2$-integrin activation on neutrophils, thus preventing the $\beta 2$ integrin interaction with intercellular adhesion molecule-1 (ICAM-1) on endothelial cells, leading to impeded neutrophil-endothelial cell adhesion and trans-endothelial migration of neutrophils; this could causatively link the elevation of FGF23 serum levels with compromised host response in systemic inflammatory diseases. ${ }^{10,13}$ Fibroblast growth factor 23 also affects other leukocytes directly where it alters monocyte function via 1 $\alpha$-hydroxylase inhibition thus decreasing 1,25dihydroxyvitamin D3 synthesis which is suggestive of a greater influence of FGF23 on inflammation and immune response regulation. ${ }^{13,20}$ 
Bearing in mind the important influence of vitamin $D$ on periodontal disease pathogenesis and the strong association of FGF23 with inflammation in addition to the regulating effect of FGF23 on vitamin D levels, we anticipated an association linking vitamin D3 and FGF23 to periodontitis. Therefore, to explore this hypothesis the present investigation was conducted to evaluate the effect of non-surgical periodontal therapy on the gingival crevicular fluid (GCF) and serum levels of vitamin D3 and FGF23 and on clinical parameters in periodontitis patients compared to healthy controls, and to recognize the correlation between them if present.

\section{Materials and Methods}

\section{Sample Size Calculation}

Sample size was calculated based upon the results of Yuci et al. 2017 using GCF vitamin D level as the primary outcome. ${ }^{21}$ The effect size was 5.7, with alpha $(\alpha)$ level $=0.05$ and beta $(\beta)$ level $=0.20(80 \%$ power $) ;$ the minimum estimated sample size was 12 patients per group for a total of 24 patients. To compensate for a drop-out rate and the use of non-parametric tests, the sample size was increased to a minimum of 15 patients per group for a total of 30 patients. Sample size calculation was performed using the computer software PS: Power and Sample Size Calculation version 3.1.2.

\section{Study Population}

The present controlled before-and-after study included a total of 30 subjects recruited from the Periodontology Clinic at the Faculty of Dentistry, Cairo University. The faculty Research Ethics Committee approved the study in line with the Helsinki Declaration of 1975. The study sample $(n=30)$ was divided into 2 groups as follows: group I consisted of 15 controls who were systematically and periodontally healthy; group II consisted of 15 subjects who were systematically healthy with stage II periodontitis. Eligible patients were informed of the purpose of the study and the benefits of participation in the study and signed a written informed consent.

\section{Inclusion Criteria}

Individuals above 30 years of age, with a minimum of 20 natural teeth excluding third molars or teeth indicated for extraction were included in the present study. The periodontally healthy group had no or minimal clinical signs of inflammation as bleeding on probing sites $\leq 10 \%$ and probing depth (PD) of $\leq 3 \mathrm{~mm}$ with no radiographic evidence of alveolar bone loss. Stage II periodontitis was diagnosed according to Papapanou et al. as having an interdental clinical attachment level (CAL) of $3-4 \mathrm{~mm}, 15-33 \%$ coronal radiographic bone loss that is mostly horizontal, no tooth loss due to periodontitis, and a maximum $P D \leq 5 \mathrm{~mm} .{ }^{22}$

\section{Exclusion Criteria}

The following were deemed grounds for exclusion: pregnancy and lactation, smoking within the previous 5 years, non-surgical periodontal therapy within the preceding 6 months or surgical periodontal therapy within the preceding 12 months, anti-inflammatory, antimicrobial, lipid-lowering (e.g. statins), and immunosuppressive therapy within the preceding 6 months, or any systemic disease that can alter the course of periodontal disease (diabetes, hypertension, cardiovascular disease, metabolic syndrome, immune disease, malignant tumor, etc.).

\section{Outcomes of the Study}

The primary outcome of the study was GCF vitamin D3 level, while secondary outcomes included $P D, C A L$, gingival index (Gl), plaque index (PI), serum level of vitD3, and GCF and serum levels of FGF23. These were measured at baseline and 3 months following periodontal therapy.

\section{Periodontal Examination and Clinical Evaluation}

At baseline, patients eligible for the study were screened via a comprehensive periodontal examination and full periodontal charts were obtained. Periapical radiographs were taken at sites of attachment loss for diagnosis of the case. Probing depth, CAL, GI, and PI were recorded at baseline and 3 months after periodontal therapy. Probing depth was measured as the distance from the base of the pocket to the free gingival margin using a University of Michigan "O" probe with Williams markings. It was recorded at the following six points around the circumference of each tooth: mesio-buccal, mid-buccal, distobuccal, disto-lingual, mid-lingual, and mesiolingual. Clinical attachment level was measured as the distance from the base of the pocket to the cemento- enamel junction at the same PD locations using the same periodontal probe. The degree of gingival inflammation was assessed by means of the Gl. It was developed for assessment of the qualitative changes in the gingiva related to the areas of the tooth which make up the total circumference of the marginal gingiva. Plaque 
Index was recorded to assess the patients' compliance with oral hygiene practices that may affect the clinical outcome measures and clinical response to periodontal therapy. ${ }^{24}$

\section{Gingival Crevicular Fluid Sample Collection}

Gingival crevicular fluid samples for subjects with a healthy periodontium were acquired from areas which showed no clinical inflammation (PI and $\mathrm{GI}=0$ ). For periodontitis patients, GCF samples were collected from the sites with the most obvious signs of clinical inflammation and the deepest PD with radiographic evidence of bone loss. Samples from the selected sites were collected as follows: all supragingival plaque was gently removed with sterile cotton rolls and the tooth was air dried gently and isolated with sterile cotton rolls to avoid contamination with saliva. Paper strips were then placed gently into the sulcus or pocket until minimal resistance was felt for 30 seconds. ${ }^{23}$ Any strip contaminated with blood or saliva was discarded. Samples were then placed into sterile Eppendorf containers, and stored immediately at $-80^{\circ} \mathrm{C}$ until biochemical analysis.

\section{Vitamin D Detection}

Vitamin D3 was assessed in all patients and controls using a human 1,25-dihydroxyvitamin D3 enzyme-linked immunosorbent assay (ELISA) kit,a which uses the double antibody sandwich technique to detect vitamin D3 in samples. Standards and test samples were added to a 96well plate which was pre-coated with human vitamin D3 antibody and they were subsequently incubated. Vitamin D3 antibodies labeled with biotin were then added and joined with streptavidin-horseradish peroxidase (HRP) to form immune complexes which were incubated and washed to eradicate the uncombined enzyme. Chromogen solutions $A$ and $B$ were then added, and the degree of color change of the liquid to yellow was observed. The human vitamin D3 captured on the plate was proportional to the density of the yellow color.

\section{Fibroblast Growth Factor 23 Detection}

Fibroblast growth factor 23 was measured using a human FGF23 ELISA kit. ${ }^{b}$ Using the doublesandwich ELISA technique, the pre-coated human FGF23 monoclonal antibody was detected by a biotin labeled polyclonal antibody. The biotin labeled antibody and the samples were added

a Shanghai Sunred Biological Technology Co., Ltd, Shanghai, China to the ELISA plate wells and were subsequently washed out with phosphate-buffered saline (PBS) or tris-buffered saline (TBS). Streptavidin-HRP conjugates were then added to the ELISA wells and $3,3^{\prime}, 5,5^{\prime}$-tetramethylbenzidine (TMB) substrate was used for coloring after the reactant was meticulously washed out with PBS or TBS. TMB reacted with streptavidin-HRP to produce a blue byproduct which was then converted to yellow under the action of the stop solution $10.16 \mathrm{M}$ sulfuric acid). The optical density was used to determine the amount of FGF23 in the samples. Values were expressed in relative units $(R U) / \mathrm{ml}$, and $1 \mathrm{RU} / \mathrm{ml}$ roughly equates to $2 \mathrm{pg} / \mathrm{ml}$ according to the manufacturer.

\section{Periodontal Therapy}

Following proper examination and diagnosis, full mouth supragingival and subgingival scaling and root planing were performed on all patients over two weeks using scalers and Gracey curettes. All patients received oral hygiene instructions including tooth brushing using the modified bass technique and the use of interdental cleansing aids (dental floss and interdental brush) to be performed at least twice per day. No local or systemic antibiotics were prescribed for the patients.

\section{Statistical Analysis}

All data were collected, tabulated, and subjected to statistical analysis. Statistical analysis was performed using the IBM SPSS Statistics software (version 16), while the Microsoft Excel software was used for data handling and graphical presentation. Measured variables were described using the mean, standard deviation (SD), range (minimum - maximum), standard error $(\mathrm{SE})$, and $95 \%$ confidence interval of the mean. Shapiro-Wilk test of normality was used to test the normality hypothesis of all quantitative variables for appropriate selection of parametric and nonparametric tests. Almost all variables were found to be normally distributed and parametric tests were thus used. Several groups were compared using one-way analysis of variance (ANOVA) followed by Dunnett's test for multiple comparisons with the control, while the paired sample $t$-test was used to compare pretreatment and posttreatment results for the same group. Results were correlated using the Pearson correlation coefficient. Significance level was set at $P<0.05(S)$, while $P<0.01$ was considered highly significant (HS). Two-tailed

b MyBioSource, Inc., San Diego, CA, USA 
tests were assumed throughout the analysis for all statistical tests.

\section{$\underline{\text { Results }}$}

A total of 30 subjects participated in the present study and were divided into two groups; group I consisted of 15 systemically healthy subjects with a healthy periodontium ( 5 males and 10 females) and a mean age of 45.4 years, while group II consisted of 15 subjects who were systematically healthy with stage II periodontitis ( 5 male and 10 females) and a mean age of 46.73. Both gender and age range closely matched in the periodontitis and control groups.
Regarding the clinical parameters at baseline and after 3 months, the Fisher's exact test was applied for PI and GI and it revealed a statistically significant decrease in PI scores postoperatively in periodontitis patients with a $P$ value of 0.0002 . A highly statistically significant decrease in $\mathrm{Gl}$ scores post-operatively was also found with a $P$ value of 0.0001 . As regards to $P D$ and $C A L$, results showed a highly statistically significant reduction $(52.86 \%)$ in PD measurements from $4.67 \pm 0.49$ at baseline to $2.20 \pm 0.68$ post-operatively $(P<0.001)$, and $a$ highly statistically significant gain $(53.57 \%)$ in CAL from $3.73 \pm 0.46$ at baseline to $1.73 \pm 0.59$ post-operatively $(P<0.001)$.

Figure 1. Descriptive data of vitamin D3 and FGF23 mean values in both GCF and serum

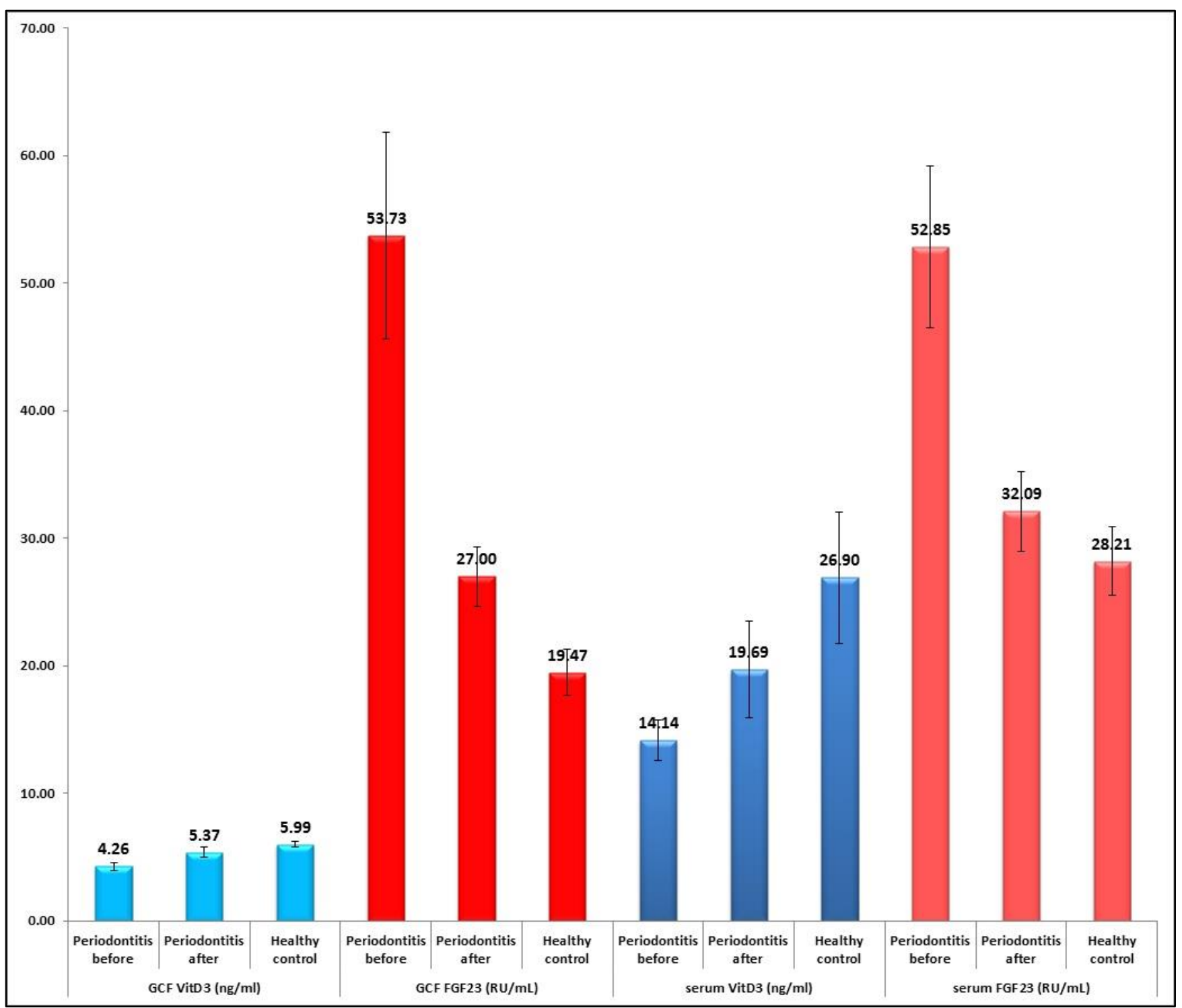

Descriptive data of vitamin D3 and FGF23 mean values in both GCF and serum are represented in Figure 1. The analysis of variance (ANOVA) test revealed a statistically significant difference between mean GCF vitamin D3, serum vitamin D3, GCF FGF23, and serum FGF23 at baseline and posttreatment in the periodontitis group and control group with $P<0.001$. Dunnett's test was used for multiple comparisons with the control and it revealed a statistically significant difference between the mean GCF vitamin D3, serum vitamin D3, GCF FGF23, and serum FGF23 levels in the control group compared to the pretreatment and posttreatment values of the periodontitis group (Table 1). In the periodontitis patients, vitamin D3 and FGF23 levels at baseline were compared to their levels three months following nonsurgical periodontal 
therapy using the paired sample t-test which revealed a highly statistically significant increase in vitamin D3 levels in both GCF and serum following treatment compared to baseline $(P<$ 0.001 ) with a $25.98 \%$ and $39.29 \%$ increase respectively (Table 2). As regards to FGF23 levels, there was a highly statistically significant decrease in their mean values in both GCF and serum following treatment compared to baseline $(P<0.001)$ with a $49.75 \%$ and $39.28 \%$ decrease respectively. The mean \% changes in vitamin D3 and FGF23 levels are represented by a bar chart in Figure 2.

Table 1. Multiple comparisons with the control using Dunnett's test

\begin{tabular}{|c|c|c|c|c|c|c|c|}
\hline \multirow{2}{*}{$\begin{array}{l}\text { Dependent } \\
\text { Variable }\end{array}$} & & & \multirow{2}{*}{$\begin{array}{l}\text { Mean } \\
\text { Difference }\end{array}$} & \multirow{2}{*}{$\begin{array}{l}\text { Standard } \\
\text { Error }\end{array}$} & \multirow{2}{*}{ P Value } & \multicolumn{2}{|c|}{$\begin{array}{c}\mathbf{9 5 \%} \text { Confidence } \\
\text { Interval }\end{array}$} \\
\hline & & & & & & $\begin{array}{l}\text { Lower } \\
\text { Bound }\end{array}$ & $\begin{array}{l}\text { Upper } \\
\text { Bound }\end{array}$ \\
\hline \multirow{2}{*}{$\begin{array}{c}\text { GCF Vitamin D3 } \\
(\mathrm{ng} / \mathrm{ml})\end{array}$} & Pretreatment & Control & -1.73 & 0.11 & $0.00000 * *$ & -1.99 & -1.47 \\
\hline & Posttreatment & Control & -0.62 & 0.11 & $0.00000 * *$ & -0.88 & -0.36 \\
\hline \multirow{2}{*}{$\begin{array}{c}\text { GCF FGF23 } \\
(\mathrm{RU} / \mathrm{ml})\end{array}$} & Pretreatment & Control & 34.27 & 1.81 & $0.00000 * *$ & 30.12 & 38.41 \\
\hline & Posttreatment & Control & 7.53 & 1.81 & $0.00030 * *$ & 3.39 & 11.68 \\
\hline \multirow{2}{*}{$\begin{array}{l}\text { Serum Vitamin } \\
\text { D3 (ng/ml) }\end{array}$} & Pretreatment & Control & -12.76 & 1.38 & $0.00000 * *$ & -15.92 & -9.59 \\
\hline & Posttreatment & Control & -7.20 & 1.38 & $0.00001^{* *}$ & -10.37 & -4.04 \\
\hline \multirow{2}{*}{$\begin{array}{l}\text { Serum FGF23 } \\
(\mathrm{RU} / \mathrm{ml})\end{array}$} & Pretreatment & Control & 24.65 & 1.60 & $0.00000 * *$ & 20.99 & 28.30 \\
\hline & Posttreatment & Control & 3.89 & 1.60 & $0.03562 *$ & 0.23 & 7.54 \\
\hline
\end{tabular}

*Significant at $P<0.05$; **highly significant at $P<0.001$

Table 2. Paired sample t-test used to compare pretreatment and posttreatment levels of vitamin D 3 and FGF23

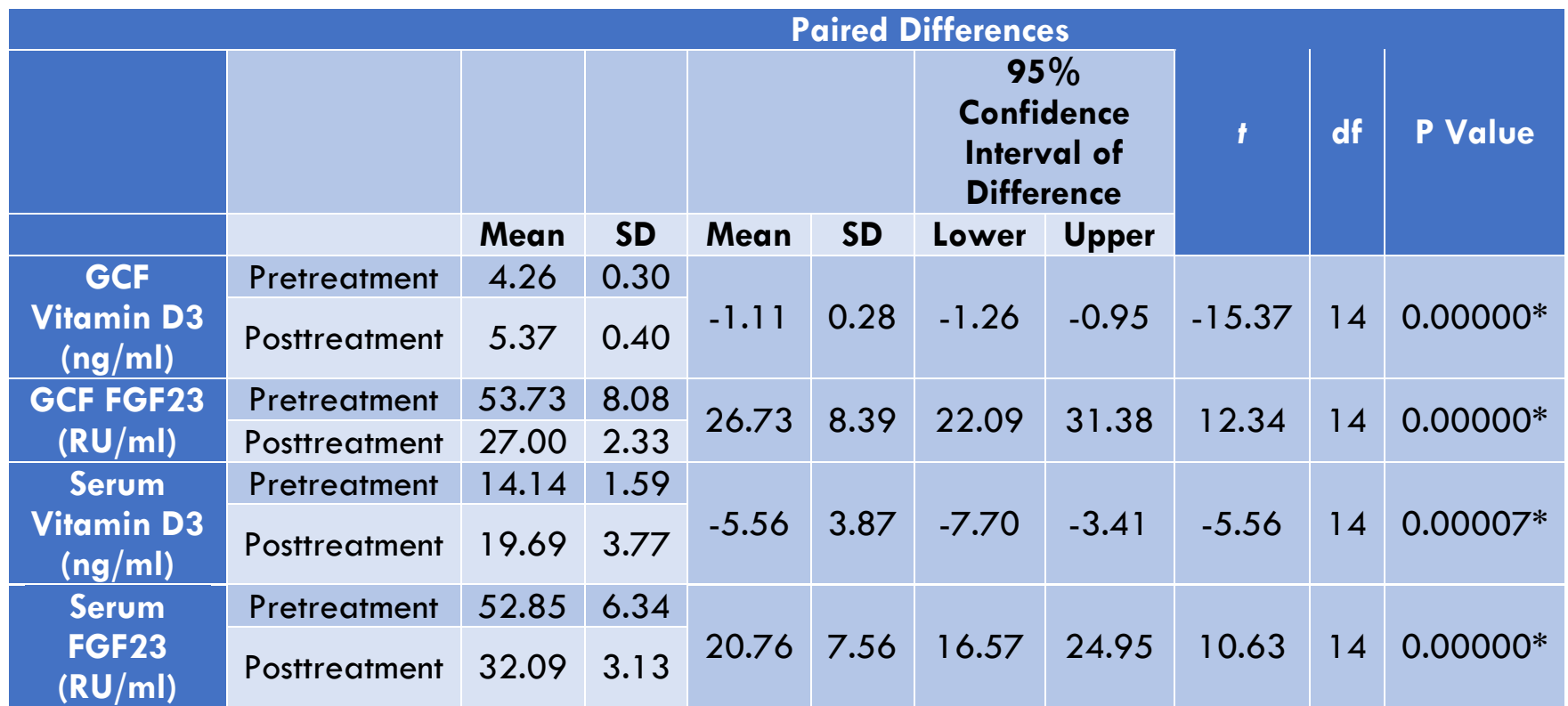

*Highly significant at $P<0.001$; df: degrees of freedom

A significant direct correlation was found between GCF and serum levels of FGF23, and a significant inverse correlation was found between serum levels of vitamin D3 and FGF23 (Table 3).

\section{Discussion}

The range of biological effects of vitamin $D$ is not confined to maintaining the homeostasis of calcium and phosphate, but it also takes a crucial part in regulating cellular proliferation, tissue differentiation, and immune function. Vitamin $D$ is also vital for a healthy periodontal status and this is supported by studies linking periodontitis to vitamin D receptor (VDR) gene polymorphisms. ${ }^{25}$ The potential role of vitamin D3 in the prevention of periodontal disease was verified by Liu et al. who stated that gingival fibroblasts and periodontal ligament cells have the ability to convert 25-hydroxyvitamin D3 to 1,25dihydroxyvitamin through their 1-a-hydroxylase activity, thereby revealing an autocrine/paracrine function of vitamin $D$ in the oral cavity. ${ }^{7}$ Vitamin D3 is the most stable form of the vitamin with a half-life of approximately 60 days; therefore, its serum levels are regarded as a reliable indicator of the vitamin $D$ status of an 
individual. ${ }^{8}$ In the present study, in addition to assessing serum levels of vitamin D3, we also assessed GCF levels of the vitamin as they would reflect closely the local changes in the periodontal environment.

The present investigation was conducted on a total of 30 subjects - of whom 15 were periodontitis patients and 15 were periodontally healthy controls - to evaluate the effect of nonsurgical periodontal treatment on clinical parameters and on the GCF and serum levels of both vitamin D3 and FGF23. Several previous studies investigated the role of vitamin $D$ in periodontal health but to the best of our knowledge no previous study explored the relation with FGF23 and its possible link with periodontitis.

Figure 2. Bar chart representing mean \% changes in vitamin D3 and FGF23 levels

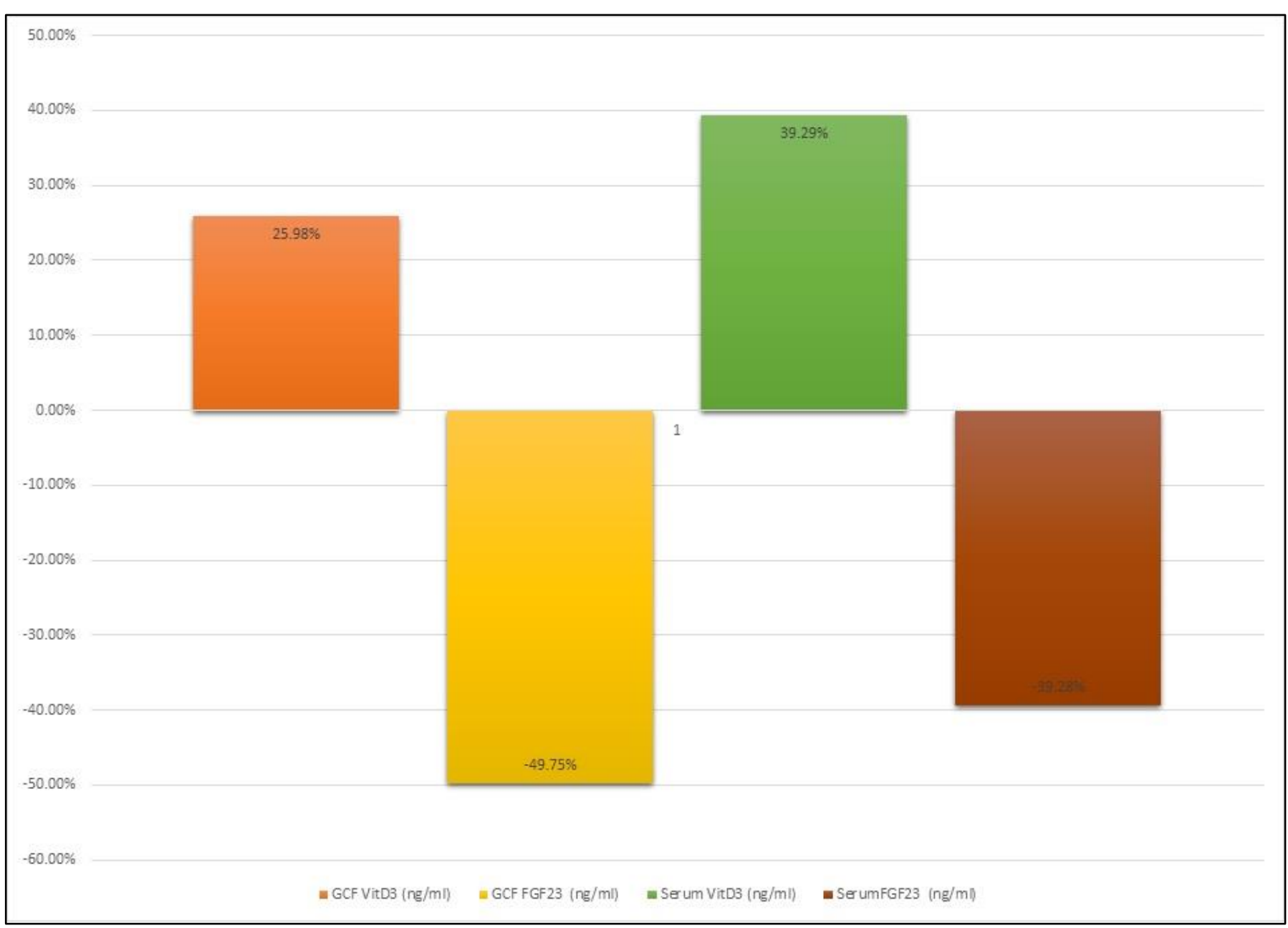

The results of the present study revealed a statistically significant decrease in PI and $\mathrm{Gl}$ scores post-operatively in periodontitis patients. Moreover, there was a $52.86 \%$ reduction in PD measurements and a $53.57 \%$ gain in CAL 3 months post-operatively and both changes were highly statistically significant. This indicates a significant improvement of periodontal condition with a decrease in clinical signs of inflammation 3 months following nonsurgical periodontal therapy.

Regarding vitamin D3 levels, our results revealed that both GCF and serum levels of vitamin D3 were significantly lower in the periodontitis group compared to the healthy control group at baseline, and a significant increase was observed 3 months following nonsurgical periodontal therapy with a $25.98 \%$ and $39.29 \%$ increase in GCF and serum respectively. These results are in accordance with
Dietrich et al. who reported that vitamin D3 levels were significantly and inversely correlated with attachment loss and that low serum levels of the vitamin were associated with signs of inflammation. ${ }^{26}$ In another study, it was reported that vitamin D3 may reduce susceptibility to gingival inflammation through its antiinflammatory effect. ${ }^{27}$

Also in line with our results, a recent study that investigated the relationship between vitamin D3 level and chronic periodontitis showed an inverse relationship between serum level of vitamin D3 and periodontal disease. ${ }^{28}$ Likewise, another study reported that there was a positive relation between serum level of vitamin D3 and periodontal health in diabetic subjects. They also found that the elimination of periodontal infection would increase the serum level of vitamin D3. ${ }^{29}$ Conflicting results were conveyed by Liu et al. who reported no difference in plasma vitamin D3 
levels between controls and chronic periodontitis patients, whereas aggressive periodontitis patients demonstrated higher plasma vitamin D3 levels than controls. ${ }^{30}$ Also in another study, it was found that GCF levels of vitamin D3 were elevated in periodontitis and rheumatoid arthritis patients compared to controls, while serum levels were not affected. ${ }^{21}$

Table 3. Correlation between vitamin D3 and FGF23 levels in GCF and serum

\begin{tabular}{|c|c|c|c|}
\hline $\begin{array}{c}\text { GCF } \\
\text { Vitamin } \\
\text { D3 }\end{array}$ & $\begin{array}{c}\text { GCF } \\
\text { FGF23 }\end{array}$ & 0.18 & 0.51156 \\
\hline $\begin{array}{c}\text { GCF } \\
\text { Vitamin } \\
\text { D3 }\end{array}$ & $\begin{array}{c}\text { Serum } \\
\text { Vitamin } \\
\text { D3 }\end{array}$ & -0.04 & 0.87380 \\
\hline $\begin{array}{c}\text { GCF } \\
\text { FGF23 }\end{array}$ & $\begin{array}{c}\text { Serum } \\
\text { FGF23 }\end{array}$ & 0.55 & $0.03486 *$ \\
\hline $\begin{array}{c}\text { Serum } \\
\text { Vitamin } \\
\text { D3 }\end{array}$ & $\begin{array}{c}\text { Serum } \\
\text { FGF23 }\end{array}$ & -0.71 & $0.00322 * *$ \\
\hline
\end{tabular}

*Significant at $\mathrm{P}<0.05$; **highly significant at $\mathrm{P}$ $<0.001$

As the present study is to our knowledge the first to address the relation of FGF23 to periodontal disease, there are no closely relatable data to compare our results with. However, FGF23 has been associated with other inflammatory diseases as chronic renal disease where inflammatory markers, as TNF $\alpha, \mathrm{IL}-6, \mathrm{C}$ reactive protein (CRP), and fibrinogen, have been reported to correlate positively with plasma FGF23 levels, which was associated with an increased severity of inflammation in such patients. ${ }^{31}$ These results agree with our findings of significantly elevated FGF23 levels in periodontitis patients that were also found to significantly decrease following periodontal therapy with resolution of clinical inflammation and $\mathrm{a} 49.75 \%$ and $39.28 \%$ reduction of FGF23 levels in GCF and serum respectively. Our results were also in line with another study which stated that FGF23 levels were elevated in children with inflammatory bowel disease during flare-ups and decreased with remission. ${ }^{32}$ Moreover, the expression of FGF23 in the heart was found to be induced by chronic inflammation in cardiac fibroblasts, suggestive of a paracrine signaling mechanism where chronic inflammation induces cardiac FGF23. 33

The association of FGF23 to periodontitis that we anticipated is supported by its strong link to inflammation as it has been found to be expressed in proinflammatory macrophages and specifically upregulated by IFN- $\gamma$ and lipopolysaccharides, which are readily available in the local periodontal environment especially during inflammation. ${ }^{34}$ Moreover, current research has established that FGF23 influences the host response to bacterial infections, possibly through inhibition of neutrophil activation and recruitment and altering monocyte function. ${ }^{13}$ It is possible that classic regulators of FGF23 as phosphate, calcium, vitamin D3, and PTH and novel factors related to pathologic circumstances, such as elevations of proinflammatory cytokines, regulate osteocyte and osteoblast production of FGF23 at variable levels and might contribute to FGF23 elevation during inflammation. ${ }^{35,36} \mathrm{~A}$ local increase in phosphate and calcium due to inflammation-induced excessive bone resorption might also stimulate FGF23 production in osteoblasts. 37,38 This could explain the local elevation of FGF23 levels in the GCF of periodontitis patients encountered in our results which significantly and directly correlated with serum level of FGF23.

While those mechanisms are important, inflammation also exerts a potent effect on FGF23 production through the regulation of iron metabolism, as chronic inflammation was reported to produce a state of "functional" iron deficiency due to sequestration of iron in the reticuloendothelial system leading to a decline in circulating iron despite sufficient total body iron stores which ultimately results in higher circulating levels of FGF23 .39 Therefore, inflammatory conditions contribute to elevated FGF23 levels and FGF23 also exhibits proinflammatory and immunomodulatory effects on macrophages and neutrophils, suggesting the existence of a "feedforward" loop whereby in inflammatory conditions, as periodontal disease, the effects of inflammation and FGF23 amplify each other, which might lead to adverse outcomes. 10,34,39

The inhibitory effect of FGF23 on vitamin $D$ synthesis may result in reduced concentrations of circulating vitamin D3 in systemic inflammatory diseases in which FGF23 has been shown to be markedly boosted. 40 This was in accordance with our results as the highest FGF23 levels were found in periodontitis patients and they were associated with the lowest vitamin D3 concentrations, and thus a significant inverse correlation between them was evident. This is also in agreement with Erben who reported that diseases characterized by excessive FGF23 blood levels are associated with low circulating vitamin D3 levels. ${ }^{19}$ Moreover, FGF23 can stimulate macrophages to express TNF $\alpha$ which plays a central role in soft and hard 
tissue destruction in periodontitis. ${ }^{41}$ It was found that vitamin D3 can inhibit FGF23-induced TNFa expression from macrophages and that the proinflammatory effects of FGF23 can be counter regulated by vitamin D3.13,34

Based on the counterregulatory effect of vitamin D3 on FGF23 proinflammatory function and the anti-inflammatory and immunomodulatory properties of vitamin D3, in addition to the endorsing effect of the vitamin on bone remodeling and promoting wound healing after periodontal surgery, we propose that sufficient intake of vitamin $D$ either in diet or as a supplement would be beneficial in the prophylaxis of periodontal disease. ${ }^{8}$ The results of the present investigation have shed light on a vital association of FGF23 with periodontal disease and vitamin D3 with periodontal health, and we recommend that this association be further explored in future research.

\section{$\underline{\text { References }}$}

1. Van der Velden U, Kuzmanova D, Chapple IL. Micronutritional approaches to periodontal therapy. J Clin Periodontol. 2011; 38 Suppl 11:142-158. https://doi.org/10.1111/j.1600$051 \mathrm{X} .2010 .01663 . \mathrm{x}$

2. Chaudhuri K, Ashok L, Sujatha GP. The sunshine of life: Vitamin D. Int J Oral Health Sci. 2015; 5:30-7. https://doi.org/10.4103/2231 6027.171171

3. Amano $Y$, Komiyama K, Makishima $M$. Vitamin $D$ and periodontal disease. J Oral Sci. 2009; 51 (1):11-20.

4. Hildebolt CF. Effect of Vitamin D and Calcium on Periodontitis. J Periodontol. 2005; 76(9): 1576-87. https://doi.org/10.1902/jop.2005.76.9. 1576

5. Stein SH, Tipton DA. Vitamin D and its impact on oral health - an update. J Tenn Dent Assoc. 2011 ; 91(2):30-33.

6. Schwalfenberg GK. A review of the critical role of vitamin $D$ in the functioning of the immune system and the clinical implications of vitamin $D$ deficiency. Mol Nutr Food Res. 2011; 55(1):96-108. https://doi.org/10.1002/mnfr.2010001 20
7. Liu K, Meng H, Hou J. Activity of 25hydroxylase in human gingival fibroblasts and periodontal ligament cells. PLoS ONE. 2012; 7(1 2):e52053. https://doi.org/10.1371/journal.pone.0 005205

8. Jagelavičienè E, Vaitkevičienè I, Šilingaitè $D$, Šinkūnaitè $E$, Daugèlaitè $G$. The Relationship between Vitamin $D$ and Periodontal Pathology. Medicina (Kaunas). 2018; 54(3):45. https://doi.org/10.3390/medicina5403 5403

9. Teles FR, Teles RP, Martin L, Socransky SS, Haffajee AD. Relationships among interleukin-6, tumor necrosis factor- $\alpha$, adipokines, vitamin $D$, and chronic periodontitis. J Periodontol. 2012; 83(9): $1183-91$. https://doi.org/10.1902/jop.2011

10. Rossaint J, Oehmichen J, Van Aken H, et al. FGF23 signaling impairs neutrophil recruitment and host defense during CKD. J Clin Invest. 2016; 126(3):962-74. https://doi.org/10.1 172/JCl83470

11. Itoh N, Ornitz DM. Evolution of the Fgf and Fgfr gene families. Trends Genet. 2004; 20( 11 1):563-9.

https://doi.org/10.1016/i.tig.2004.08.0 00

12. Hu MC, Shiizaki K, Kuro-o M, Moe OW. Fibroblast growth factor 23 and Klotho: physiology and pathophysiology of an endocrine network of mineral metabolism. Annu Rev Physiol. 2013; 75:503-33. https://doi.org/10.1146/annurevphysiol-03021 2-183727

13. Richter B and Faul C. FGF23 Actions on Target Tissues-With and Without Klotho. Front Endocrinol (Lausanne). 2018; 9:189. https://doi.org/10.3389/fendo.2018.0 0018

14. Erben RG, Andrukhova O. FGF23 regulation of renal tubular solute transport. Curr Opin Nephrol Hypertens. 2015; 24(5):450-6. https://doi.org/10.1097/MNH.000000 0000000000 
15. Shimada T, Yamazaki Y, Takahashi $M$, et al. Vitamin $D$ receptor-independent FGF23 actions in regulating phosphate and vitamin D metabolism. Am J Physiol Renal Physiol. 2005; 289(5):F1088-95. https://doi.org/10.1152/ajprenal.0047 0.2004

16. Olauson $H$, Lindberg $K$, Amin $R$, et al. Parathyroid-specific deletion of Klotho unravels a novel calcineurin-dependent FGF23 signaling pathway that regulates PTH secretion. PLoS Genet. 2013; 9(12):e 1003975.

https://doi.org/10.1371/journal.pgen.1 100397

17. Murali SK, Roschger P, Zeitz U, Klaushofer K, Andrukhova O, Erben RG. FGF23 Regulates Bone Mineralization in a 1,25(OH)2 D3 and Klotho-Independent Manner. J Bone Miner Res. 2016; $31(1): 129-42$.

https://doi.org/10.1002/ibmr.2606

18. Addison WN, Azari F, Sørensen ES, Kaartinen MT, McKee MD. Pyrophosphate inhibits mineralization of osteoblast cultures by binding to mineral, upregulating osteopontin, and inhibiting alkaline phosphatase activity. J Biol Chem. 2007; 282(21):15872-83. https://doi.org/10.1074/jbc.M7011162 70

19. Erben RG. Physiological Actions of Fibroblast Growth Factor-23. Front Endocrinol (Lausanne). 2018; 9:267. https://doi.org/10.3389/fendo.2018.0 0026

20. Bacchetta J, Sea JL, Chun RF, et al. Fibroblast growth factor 23 inhibits extrarenal synthesis of 1,25dihydroxyvitamin $D$ in human monocytes. J Bone Miner Res. 2013; 28(1):46-55. https://doi.org/10.1002/jbmr.1740

21. Balci Yuce H, Gokturk O, Aydemir Turkal $H$, Inanir A, Benli I, and Demir $O$. Assessment of local and systemic 25hydroxy-vitamin D, RANKL, OPG, and TNF levels in patients with rheumatoid arthritis and periodontitis. J Oral Sci. 2017; 59(3):397-404. https://doi.org/10.2334/josnusd.160677
22. Papapanou PN, Sanz M, Buduneli N, et al. Periodontitis: Consensus report of workgroup 2 of the 2017 World Workshop on the Classification of Periodontal and Peri-Implant Diseases and Conditions. J Periodontol. 2018; 89 Suppl 1: S173- S182. https://doi.org/10.1002/JPER.17-0721

23. Griffiths GS. Formation, collection and significance of gingival crevice fluid. Periodontol 2000. 2003; 31:32-42.

24. Silness J, Loe H. Periodontal Disease in Pregnancy. II. Correlation between Oral Hygiene and Periodontal Condtion. Acta Odontol Scand. 1964; 22:121-135. https://doi.org/10.3109/0001635640 0001635

25. Laine ML, Loos BG, Crielaard W. Gene polymorphisms in chronic periodontitis. Int J Dent. 2010; 2010:324719. https://doi.org/10.1 155/2010/32471 9

26. Dietrich T, Joshipura KJ, Dawson-Hughes B, Bischoff-Ferrari HA. Association between serum concentrations of 25hydroxyvitamin $D_{3}$ and periodontal disease in the US population. Am J Clin Nutr. $\quad 2004 ; \quad 80(1): 108-113$. https://doi.org/10.1093/ajen/80.1.108

27. Dietrich T, Nunn M, Dawson-Hughes $B$, Bischoff-Ferrari HA. Association between serum concentrations of 25 hydroxyvitamin $D$ and gingival inflammation. Am J Clin Nutr. 2005; 82(3):575-80.

https://doi.org/10.1093/ajen.82.3.575

28. Eshghi R, Maybodi FR, Khabazian A, Shahhosseini $S$. Association between serum levels of vitamin $D$ and chronic periodontitis in premenopausal women in Yazd. Caspian J Dent Res. 2016; 5:47-51. https://doi.org/10.22088/cjdr.5.1.47

29. Antonoglou $G$, Knuuttila $M$, Niemelä O, et al. Serum 1,25(OH)D level increases after elimination of periodontal inflammation in T1DM subjects. J Clin Endocrinol Metab. 2013; 98(10):3999-4005. https://doi.org/10.1 210/ic.2013-1906 
30. Liu K, Meng $H$, Lu R, et al. Initial periodontal therapy reduced systemic and local 25-hydroxy vitamin $D(3)$ and interleukin-1 beta in patients with aggressive periodontitis. J Periodontol. 2010; $81(2): 260-6$. https://doi.org/10.1902/jop.2009.090 090

31. Sato H, Kazama JJ, Murasawa A, et al. Serum Fibroblast Growth Factor 23 (FGF23) in Patients with Rheumatoid Arthritis. Intern Med. 2016; 55(2):121-6. https://doi.org/10.2169/internalmedicin i.55.5507

32. El-Hodhod MA, Hamdy AM, Abbas AA, Moftah SG, Ramadan AA. Fibroblast growth factor 23 contributes to diminished bone mineral density in childhood inflammatory bowel disease. BMC Gastroenterol. 2012; 12:44. https://doi.org/10.1 186/1471-230X12-44

33. Leifheit-Nestler $M$, Haffner D. Paracrine Effects of FGF23 on the Heart. Front Endocrinol (Lausanne). 2018; 9:278. https://doi.org/10.3389/fendo.2018.0 0027

34. Han X, Li L, Yang J, King G, Xiao Z, Quarles LD. Counter-regulatory paracrine actions of FGF-23 and $1,25(\mathrm{OH})_{2} D$ in macrophages. FEBS Lett. 2016; 590(1):53-67. https://doi.org/10.1002/18733468.12040

35. David V, Martin A, Isakova T, et al. Inflammation and functional iron deficiency regulate fibroblast growth factor 23 production. Kidney Int. 2016; 89(1):135-46.

https://doi.org/10.1038/ki.2015.290

36. Ito $N$, Wijenayaka $A R$, Prideaux $M$, et al. Regulation of FGF23 expression in IDGSW3 osteocytes and human bone by proinflammatory stimuli. Mol Cell Endocrinol. 2015; 399:208-18. https://doi.org/10.1016/i.mce.2014.10. 007

37. David D, Dai B, Martin A, Huang J, Han X, Quarles LD. Calcium regulates FGF-23 expression in bone. Endocrinology. 2013;
154(1 2):4469-82.

https://doi.org/10.1210/en.2013-1627

38. Yamazaki $M$, Kawai $M$, Miyagawa $K$, et al. Interleukin-1-induced acute bone resorption facilitates the secretion of fibroblast growth factor 23 into the circulation. J Bone Miner Metab. 2015; 33(3):342-54.

https://doi.org/10.1007/s00774-0140598-2

39. Francis C, David V. Inflammation regulates fibroblast growth factor 23 production. Curr Opin Nephrol Hypertens. 2016; 25(4): 325-32. https://doi.org/10.1097/MNH.000000 0000000000

40. Augustine $M V$, Leonard $M B$, Thayu $M$, et al. Changes in vitamin D-related mineral metabolism after induction with anti-tumor necrosis factor- $\alpha$ therapy in Crohn's disease. J Clin Endocrinol Metab. 2014; 99(6):E991-8.

https://doi.org/10.1210/ic.2013-3846

41. Masuda Y, Ohta H, Morita $Y$, et al. Expression of Fgf23 in activated dendritic cells and macrophages in response to immunological stimuli in mice. Biol Pharm Bull. 2015; 38(5):687-93. https://doi.org/10.1248/bpb.b 1400276

Conflicts of interest: The authors declared no conflicts of interest related to this work.

\section{Corresponding author:}

Dr. Dalia M. Ghalwash

Associate Professor, Department of Oral

Medicine and Periodontology

Faculty of Dentistry

The British University in Egypt

Shorouk City, Postal Code 11835

Cairo, Egypt

E-mail: dalia.ghalwash@bue.edu.eg

Phone: +201005120159

Edited by Professor Ahmed Y. Gamal

This is an open access article distributed under the Creative Commons Attribution-

Noncommercial-NoDerivatives 4.0 International (CC BY-NC-ND 4.0) License. 